\title{
Desenvolvimento de uma Sonda Atmosférica Sem Fio para estudos ambientais de baixo custo
}

\author{
Development of a Wireless Atmospheric Probe for environmental cheap \\ studies
}
Giorgio Arlan da Silva Picanço1, Julio Tota da Silva², Raoni Aquino Silva de Santana ${ }^{3}$ e Roseilson Souza do Vale 3
${ }^{1}$ Instituto de Engenharia e Geociências, Universidade Federal do Oeste do Pará, Santarém, Brasil giorgiopicanco@gmail.com
2Instituto de Engenharia e Geociências, Universidade Federal do Oeste do Pará, Santarém, Brasil totaju@gmail.com
${ }^{3}$ Instituto de Engenharia e Geociências, Universidade Federal do Oeste do Pará, Santarém, Brasil raoniass@gmail.com; roseilsondovale@gmail.com

\begin{abstract}
Resumo
Este trabalho apresenta o desenvolvimento de uma sonda atmosférica wireless, projetada para auxiliar estudos ambientais de longa duração com poucos recursos financeiros. O trabalho é baseado no conceito de Redes de Sensores Sem Fio, no qual vários sensores dispõem-se espacialmente dispersos em uma determinada região. Facilitando o monitoramento de vastas áreas sem a necessidade de grandes estruturas físicas de comunicação e energia, como cabos e torres. O protótipo, construído com material de baixo custo, capta dados de temperatura, pressão e umidade relativa do ar, transmitindo essas informações em tempo real a um receptor remoto via radiofrequência, a uma distância de até $1 \mathrm{~km}$. O protótipo ainda é equipado com um sistema fotovoltaico, capaz de lhe garantir autonomia energética, fator imprescindível para estudos de longa duração. Para avaliar a eficiência do protótipo, foram realizados testes de correlação com uma estação METPAK II (Gill Instruments), visando simular o funcionamento contínuo dos sensores in situ. Os testes apresentam correlações significativas entre as variáveis de pressão atmosférica (98\%), umidade relativa ( $87 \%$ ) e temperatura do ar (97\%). Os testes realizados garantem um bom grau de confiabilidade ao protótipo; podendo servir como alternativa para projetos de monitoramento ambiental e de Redes de Sensores Sem Fio.
\end{abstract}

Palavras-chave: Monitoramento ambiental. Sistemas de tempo real. Plataforma sensorial. Sistemas embarcados.

\begin{abstract}
This paper presents the development of a wireless atmospheric probe, designed to assist long-term environmental studies with limited financial resources. The work is based on the concept of Wireless Sensor Networks in which multiple sensors are arranged spatially in a particular region. Facilitating the monitoring of large areas without the need for large physical structures of communication and power, as cables and towers. The prototype, built with cheap material, captures temperature data, pressure and humidity, transmitting this information in real time to a remote receiver via radio frequency to a distance of $1 \mathrm{~km}$. The prototype is also equipped with a photovoltaic system capable of guaranteeing energy independence, an essential factor for long-term studies. To evaluate the efficiency of the prototype, correlation tests were performed with a Metpak station II (Gill Instruments), to simulate the continuous operation of the sensors in situ. The tests show significant correlations between atmospheric pressure variables (98\%), relative humidity (87\%) and air temperature (97\%). The tests ensure a good degree of reliability to the prototype; can serve as an alternative to environmental monitoring projects and Wireless Sensor Networks.
\end{abstract}




\section{Introdução}

Devido às constantes mudanças de clima e tempo no cenário amazônico, o monitoramento das variáveis ambientais se mostra uma ferramenta muito importante para a compreensão dos efeitos dos processos naturais que abrangem o sistema biosferaatmosfera; ao qual ainda se atribuem inúmeras incógnitas, em caráter geográfico e antrópico. Em resposta a essa necessidade, estudos são feitos a partir da implementação de estações meteorológicas em pontos específicos das regiões de interesse, fornecendo informações acerca de variáveis como temperatura local, umidade relativa do ar e pressão atmosférica; e ainda dados sobre materiais particulados, dióxido e monóxido de carbono, direção e velocidade do vento, radiação solar, entre outros (Salvioni and Fruett, 2013).

Com o advento dos microssensores e das tecnologias de telecomunicação, surge uma tendência de dinamização nas técnicas de monitoramento ambiental; não só em se tratando das plataformas aquisição, mas também, nos meios de observação (Couto Braga, 2010). Atualmente, existem dezenas de plataformas de aquisição de dados atmosféricos sem fio no mercado. A maioria delas obedece ao diagrama estrutural das Redes de Sensores Sem Fio (RSSF), que é caracterizado pela coleta, processamento e transmissão de informações de um ou mais sensores, alimentados por uma bateria independente (Dulman et al., 2006). Porém, esses instrumentos, ocasionalmente, seguem padrões comerciais, tornando sua aquisição, muitas vezes, economicamente inviável para estudos em larga escala.

Em oposição a estes fatores, foi desenvolvida uma Sonda Atmosférica Sem Fio (SASF) de baixo custo capaz de medir variáveis ambientais em áreas de difícil acesso, sem a necessidade de cabos e de estruturas complexas de energia; contando com a tecnologia de transmissão de dados por radiofrequência e trabalhando de forma autônoma com a utilização de um sistema fotovoltaico. Dessa forma, contribuindo para a busca por uma maior dinâmica do processo de aquisição de dados atmosféricos.

\section{Metodologia}

O modelo físico de sistemas embarcados sem fio é a mais simples plataforma aplicável a locais remotos e de difícil acesso, por integrar aquisição, processamento e transmissão de dados em um único dispositivo (Hill, 2003; Ickes et al., 2013). Com a integração de uma ou mais sondas atmosféricas ao receptor central via rede wireless, é possível monitorar uma área extensa sem o uso de cabos e complicadas instalações.

A SASF desenvolvida consiste basicamente em quatro componentes principais: sensores, um microcontrolador, dispositivo de comunicação e uma bateria alimentada por um sistema fotovoltaico (Figura 1).

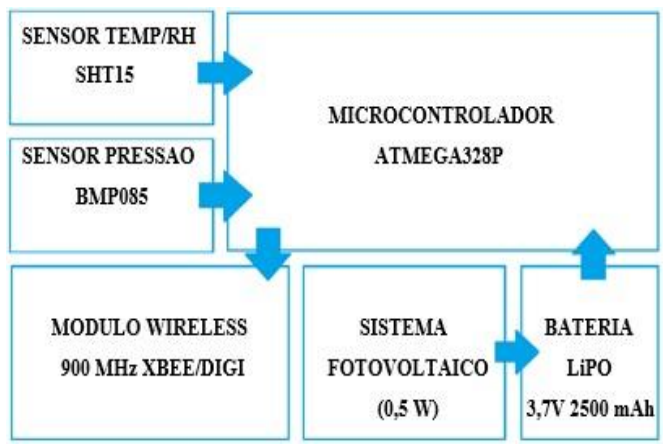

Figura 1 - Diagrama com os principais componentes da SASF

A maioria das sondas atmosféricas programáveis do mercado é estruturada com base em placas comerciais acopláveis, chamadas shields. Essas placas são desenvolvidas com o propósito de interagir umas com as outras, adicionando novas funções a um aparelho básico. Isso proporciona uma expansão nas possibilidades dos sistemas embarcados baseados em plataformas de desenvolvimento. Porém, na implementação desses sistemas, a utilização de shields acaba tornando o projeto mais caro, devido à quantidade de módulos que devem ser 
conectados para se conseguir uma determinada função. A sonda descrita neste trabalho foi projetada para funcionar com o mínimo de componentes, visando diminuir custos de produção, mas sem ocasionar perdas na qualidade dos dados.

O protótipo (Figura 2) utiliza dois sensores da Sparkfun Electronics: BMP085, capaz de obter dados de pressão atmosférica com acurácia de 0,2 hPa, e o SHT15, um sensor de temperatura e umidade relativa com acurácia de 0,3 e 0,02, respectivamente. O microcontrolador utilizado foi o Atmega328P, que possui microprocessador RISC de 8 bits, 28 pinos, memória flash de 32k, 23 portas I/O, sendo 6 ADC, voltagem de operação entre $1.8 \mathrm{~V}$ a $5 \mathrm{~V}$ e uma linguagem padrão de programação, originada em Wiring que é essencialmente, $\mathrm{C} / \mathrm{C}++$. O software embarcado foi desenvolvido a partir de bibliotecas da plataforma Arduino.

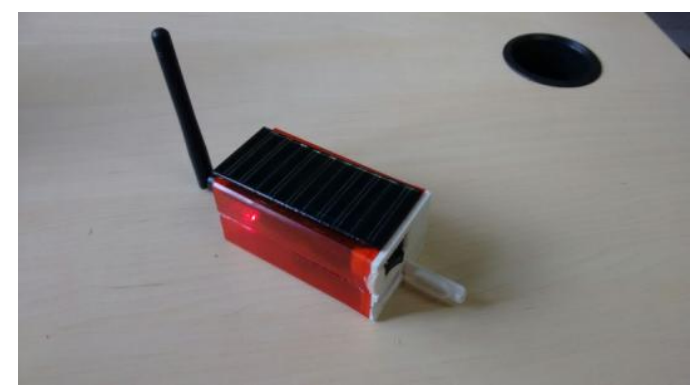

Figura 2 - Protótipo da Sonda Atmosférica Sem Fio (SASF) construído com material de baixo custo

Foi utilizado um módulo de comunicação Xbee-PRO 900HP, fabricado pela empresa DIGI. Esse modelo opera na frequência de 900 $\mathrm{MHz}$, e possibilita uma comunicação simples entre pontos, através de uma interface UART por onde dados podem ser transmitidos $\mathrm{e}$ recebidos (Maxtream, 2006).

A bateria utilizada é de Lítio-polímero, também utilizadas em smartphones, e outros portáteis, são recarregáveis e tem o dobro da capacidade das baterias de níquel. Além de não possuírem o efeito memória (não viciam) elas são muito compactas. Para a alimentação da sonda, foi utilizado um modelo de 3,7 V e $2500 \mathrm{mAh}$, com carregamento via painel solar $(0,5 \mathrm{~W})$.

\section{Resultados}

Para avaliar a eficiência da SASF, foram realizados testes de alcance e comparação com uma estação meteorológica Metpak II, simulando o funcionamento contínuo da estação em campo. O Objetivo dos testes foi determinar a distância de alcance máximo da transmissão de dados e a resposta dos sensores às variações no ambiente em comparação a estação Metpak II.

3.1 Testes de comparação

Os testes foram realizados em uma torre instrumentada no Campus Tapajós da Universidade Federal do Oeste do Pará. A SASF foi colocada a $5 \mathrm{~m}$ na torre juntamente com a estação Metpak II usada como referência. As medidas foram realizadas durante um período de 12 horas (entre 20:00 e 08:00) e foram gerados alguns gráficos (Figura 3). A correlação entre as variáveis da SASF e a estação Metpak II foram de $87 \%$ para umidade relativa do ar, $98 \%$ pressão atmosférica e $97 \%$ para temperatura do ar.

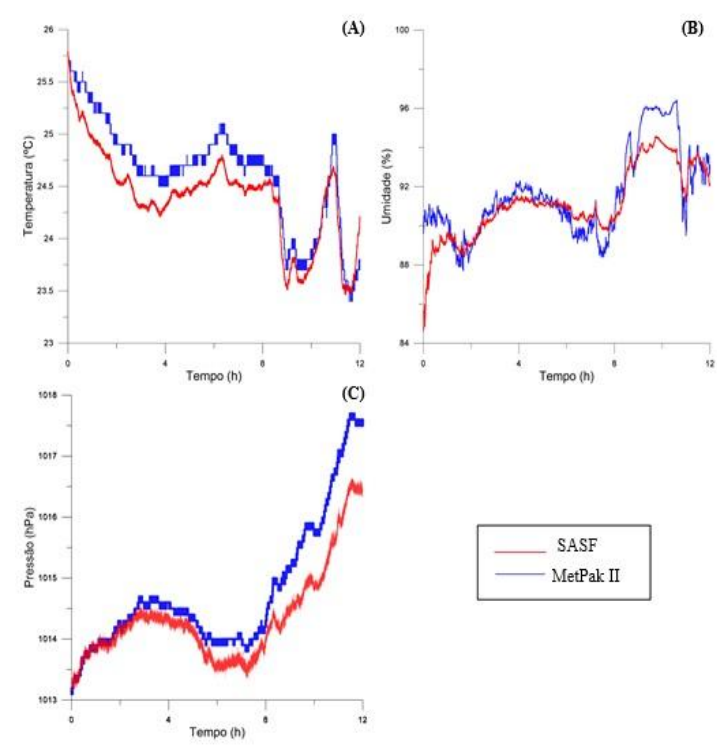

Figura 3 - Gráficos dos testes de comparação entre a SASF e a estação Metpak II para as variáveis Temperatura (A), Umidade Relativa (B) e Pressão Atmosférica (C) para um período de 12 horas de amostragem 


\subsection{Testes de alcance}

Para mensurar o alcance máximo da conexão estável entre o transmissor e o receptor, foi realizado um teste com a sonda em um ambiente com desníveis topográficos e estruturas que pudessem interferir na intensidade do sinal. O protótipo atingiu um alcance - sem perda de dados - de $839.64 \mathrm{~m}$ (figura 4). Os testes foram realizados na zona urbana de Santarém - PA, no bairro onde se encontra o Campus Tapajós - UFOPA, em condições de tempo normais, em constante movimentação em linha reta.

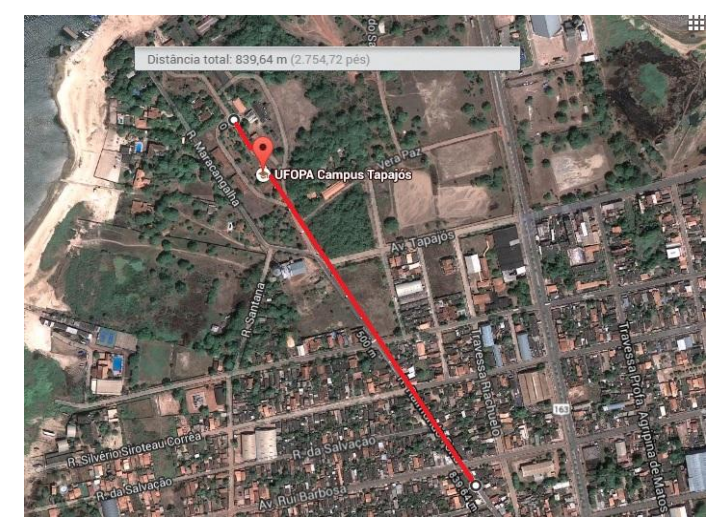

Figura 4 - Teste de alcance máximo do protótipo da SASF na UFOPA - Campus Tapajós

\section{Conclusões}

Nota-se para a variável umidade relativa certa divergência entre os sensores nas primeiras horas de funcionamento (Figura 4B). Provavelmente, essa diferença ocorre devido aos diferentes tempos de resposta dos sensores, ocasionando certa demora no auto ajuste da SASF. Porém, após certo tempo essa diferença diminui.

Dado à semelhança da qualidade dos dados nos testes realizados e o valor gasto para o desenvolvimento do protótipo, conclui-se que a sonda desenvolvida é viável para estudos ambientais, apresenta boa relação custo-benefício e atinge as expectativas do projeto.
Gostaríamos de agradecer ao CNPQ, pela bolsa de inovação tecnológica, Dr. Rodrigo da Silva e Dr. David Fitzjarrald pelo apoio na construção do protótipo.

\section{Referências}

SALVIONI, M. S; FRUETT, F. Monitoramento Ambiental através de Rede de Sensores Sem Fio de Baixo Custo. Anais XVI Simpósio Brasileiro de Sensoriamento Remoto - SBSR, INPE, 2013.

COUTO BRAGA, T. Monitorização Ambiental em Espaços Florestais com Rede de Sensores Sem Fios. Dissertação (Mestrado em Engenharia de Telecomunicações). Centro de Competência de Ciências Exactas e da Engenharia - Universidade da Madeira, 2010.

DULMAN, S.; BRAM, D.; HAVINGA, P. Range-Based Localization in Mobile Sensor Networks. Wireless Sensor Networks. p. 164179. Springer Berlin Heidelberg, 2006.

HILL, J. L. System architecture for Wireless Sensor Networks. Tese (Doutorado). University of California, 2003.

ICKES, N.; IANNUCCI, P.; JACOBS, S.; PAIDIMARRI, A.; WANG, X.; YAUL, F.; BALAKRISHNAN, H.; GLEASON, K. K.; CHANDRAKASAN, A. P. Self-powered Long-range Wireless Microsensors for Industrial Applications. MTL Annual Research Report/ Massachusetts Institute of Technology, 2013.

Maxstream. XBee/Xbee Pro OEM RF Modules Product Manual, Maxstream, 2006.

\section{Agradecimentos}

